\title{
Central serous chorioretinopathy secondary to childbirth
}

\author{
Nashila Hirji, Lynda Watt, Emma Richardson \\ Ophthalmology Department, Queen Mary's Hospital, Sidcup, Kent, UK \\ Correspondence to Dr Nashila Hirji, nashila@doctors.org.uk
}

\section{Summary}

A previously healthy 37-year-old woman presented with decreased vision in the right eye, noted suddenly during childbirth. Fundus examination revealed elevation at the right macula, and optical coherence tomography confirmed central serous chorioretinopathy in the right eye. No intervention was undertaken, and the symptoms and clinical findings resolved spontaneously over 2 months.

\section{BACKGROUND}

Central serous chorioretinopathy (CSC) has previously been reported as a complication of pregnancy. However, symptoms most commonly begin prior to labour, resolving by, or soon after, birth. Rarely, CSC has been noted to occur soon after childbirth. In all the case reports reviewed of CSC developing before or soon after childbirth, the condition has arisen in the context of a patient with a complicated pregnancy, usually due to eclampsia or pre-eclampsia. We report a case which is unusual in that that the patient developed symptoms of CSC during childbirth in the absence of any obstetric complications.

\section{CASE PRESENTATION}

A previously fit and well 37-year-old woman was referred to eye casualty by the obstetric team 5 days after delivery. She reported blurred vision in the right eye, which had developed during labour. The patient stated that the visual disturbance was noted suddenly during the second stage of labour, and that her vision had been completely normal previously. There were no other associated symptoms, and she otherwise felt well in herself. There was no significant medical or ophthalmic history, and the pregnancy had been uncomplicated, with no abnormal clinical findings in the antepartum period. Haematological parameters and urinalysis results had also been within normal limits during this time. At presentation, best-corrected visual acuity (BCVA) was 6/9 bilaterally. Blood glucose and blood pressure were within normal limits. Colour vision and pupillary responses were normal. Anterior segment examination was unremarkable. The left fundus appeared normal, but the right showed macular elevation.

\section{INVESTIGATIONS}

Optical coherence tomography (OCT) of the right eye showed subretinal fluid consistent with CSC (figure 1). Blood tests and urinalysis were performed by the obstetric team in the postpartum period, and revealed no significant abnormality which could signify an underlying complication.

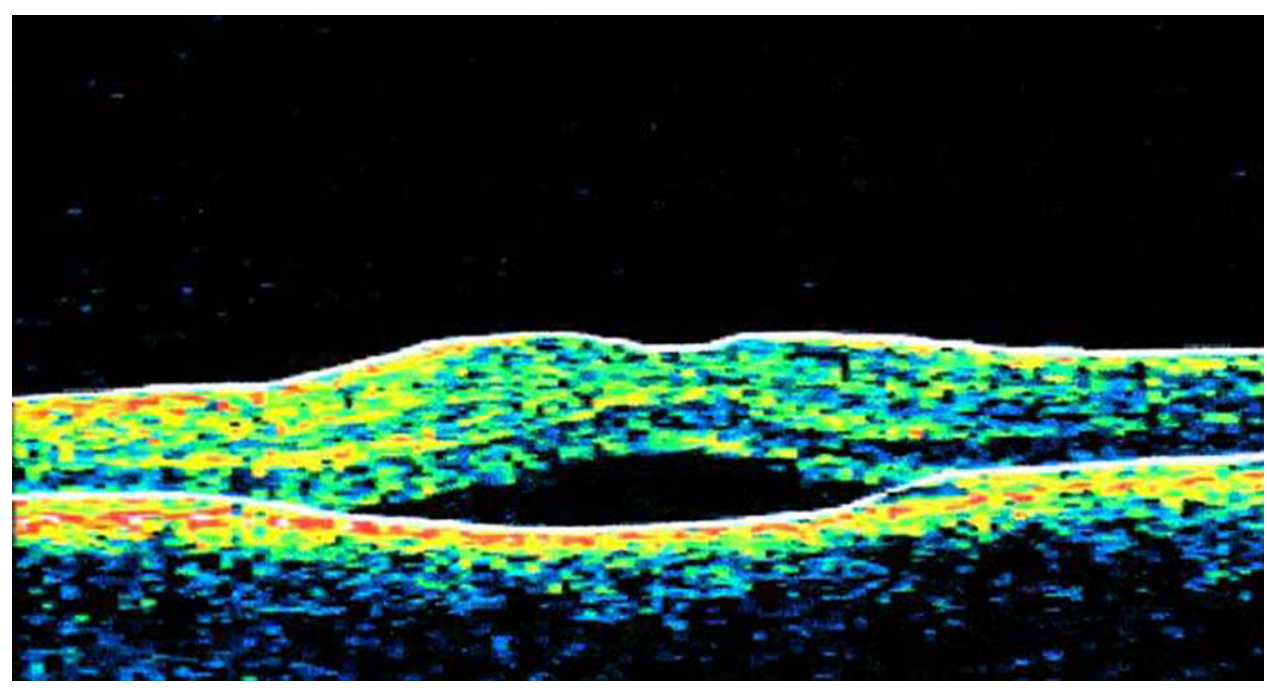

Figure 1 Optical coherence tomography of the right fundus at presentation. The scan shows subretinal fluid at the macula, consistent with central serous chorioretinopathy. 


\section{BMJ Case Reports}

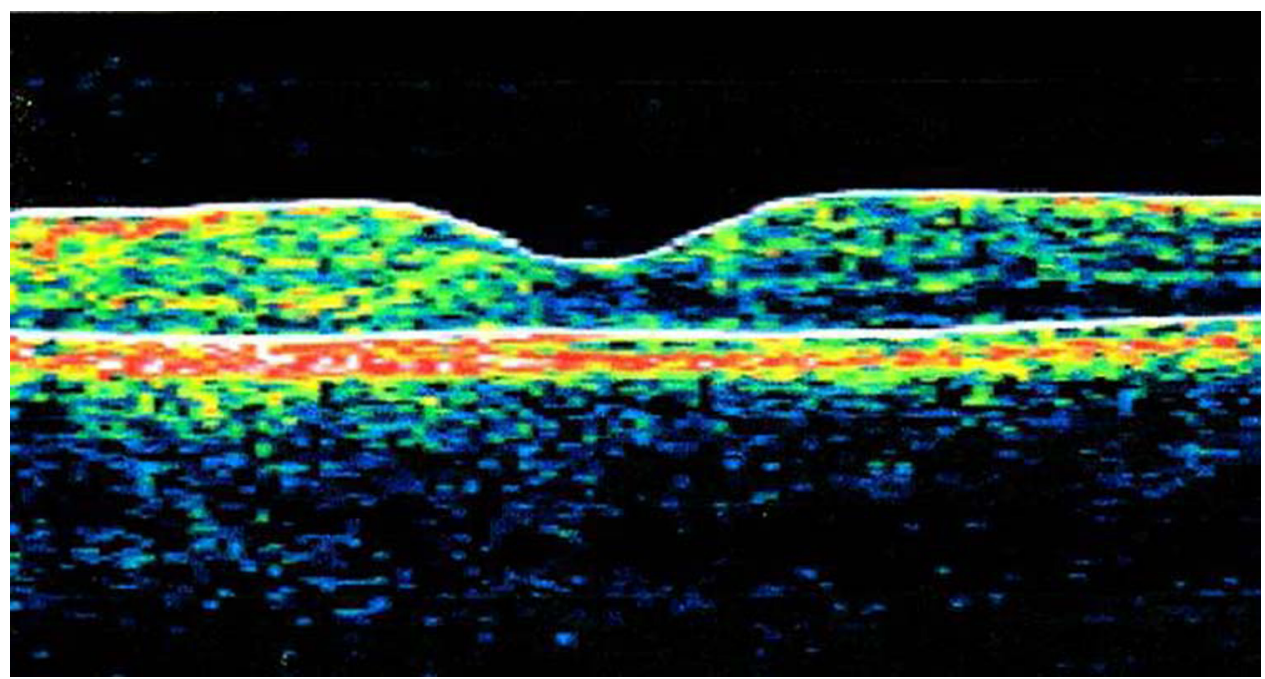

Figure 2 Optical coherence tomography of the right fundus at 2-month follow-up. The scan shows complete resolution of the subretinal fluid.

\section{TREATMENT}

No treatment was undertaken. The patient was reassured that her vision should gradually improve over time, as occurs in most cases of CSC.

\section{OUTCOME AND FOLLOW-UP}

At 2-month follow-up, the BCVA in the right eye had improved to 6/6. Fundus examination showed complete resolution of the earlier macular changes, and OCT confirmed resolution of the subretinal fluid (figure 2). The patient was subsequently discharged.

\section{DISCUSSION}

CSC is a known pregnancy-related complication, although previous reports of CSC during pregnancy have been associated with pregnancy-induced hypertension $(\mathrm{PIH})$, where CSC is thought to result from choroidal ischaemia. ${ }^{12}$ Other reports have been in association with HELLP syndrome (Haemolytic anaemia, Elevated Liver enzymes and Low Platelets), ${ }^{3}$ which is related to severe PIH. CSC can occur in any trimester of pregnancy, can be unilateral or bilateral, and usually resolves by the end of pregnancy or soon after delivery. On rare occasions, it has been reported in the postpartum period, up to 4 weeks after delivery, similarly in association with underlying systemic pathologies. There are no reports of CSC occurring during an uncomplicated pregnancy, or with symptom onset intrapartum. Our patient had no antepartum history suggestive of $\mathrm{PIH}$ or HELLP. However, as a result of her reduced visual acuity which was first noted during childbirth, she was admitted by the obstetric team for several days following delivery, and during this time was thoroughly investigated for an underlying systemic pathology that could have been responsible for her symptoms. Clinical observations and examination findings during the admission were not suggestive of either PIH or HELLP, and similarly, haematological and biochemical parameters, as well as urinalysis results were not consistent with either pathology. This led us to believe that the CSC may have developed through an alter- native mechanism in this patient. Recent studies using indocyanine green angiography suggest that the possible primary pathology in CSC is in the choroidal vessels, ${ }^{4}$ and that venous congestion can lead to hyperpermeability of choroidal vessels resulting in CSC. ${ }^{5}$ Our patient reported pushing for an extended period during the second stage of labour (almost $3 \mathrm{~h}$ ), and we therefore suggest that the resulting raised venous pressure and subsequent venous congestion may have caused her to develop CSC.

In summary, it appears that CSC can occur during labour. Anecdotally, blurred vision is often reported postpartum, but there is a notable lack of OCT studies on such patients, and symptoms are frequently attributed to hormonal changes, particularly as they resolve spontaneously over time following delivery. Our finding implies that ocular imaging of women with such symptoms may be warranted in establishing a diagnosis and supporting our observations.

\section{Learning points}

- Central serous chorioretinopathy (CSC) is a known complication of pregnancy in patients with underlying disease or obstetric complications.

- Our patient demonstrates that CSC may also occur in a healthy woman with an uncomplicated pregnancy, and we propose that this may be due to the process of childbirth itself.

- Blurred vision is often reported by women following childbirth, but is rarely investigated, particularly as it has a tendency to settle spontaneously.

- Our report suggests that CSC following childbirth may be more common than realised, and that a thorough eye examination should be performed in such patients to ensure a diagnosis is not missed.

Competing interests None

Patient consent Obtained. 


\section{BMJ Case Reports}

\section{REFERENCES}

1. Sheth BP, Mieler WF. Ocular complications of pregnancy. Curr Opin Ophthalmol 2001:12:455-63.

2. Valluri S, Adelberg DA, Curtis RS, et al. Diagnostic indocyanine green angiography in pre-eclampsia. Am J Ophthalmol 1996;122:672-7.

3. Gupta LY, Mansour SE. Bilateral bullous retinal detachment as a complication of the HELLP syndrome. Can J Ophthalmol 1994;29:242-5.
4. Guyer DR, Yannuzzi LA, Slakter JS, et al. Digital indocyanine green videoangiography of central serous chorioretinopathy. Arch Ophthalmol 1994;112:1057-62.

5. Prpnte C, Flammer J. Choroidal capillary and venous congestion in central serous chorioretinopathy. Am J Ophthalmol 1996;121:26-34.

This pdf has been created automatically from the final edited text and images.

Copyright 2010 BMJ Publishing Group. All rights reserved. For permission to reuse any of this content visit

http://group.bmj.com/group/rights-licensing/permissions.

BMJ Case Report Fellows may re-use this article for personal use and teaching without any further permission.

Please cite this article as follows (you will need to access the article online to obtain the date of publication).

Hirji N, Watt L, Richardson E. Central serous chorioretinopathy secondary to childbirth. BMJ Case Reports 2010;10.1136/bcr.10.2010.3387, date of publication

Become a Fellow of BMJ Case Reports today and you can:

- Submit as many cases as you like

- Enjoy fast sympathetic peer review and rapid publication of accepted articles

Access all the published articles

- Re-use any of the published material for personal use and teaching without further permission

For information on Institutional Fellowships contact consortiasales@bmjgroup.com

Visit casereports.bmj.com for more articles like this and to become a Fellow 